\title{
EISCSA News
}

\section{Messages from the secretariat}

Dear members and readers of our official journal 'Isokinetics \& Exercise Science',

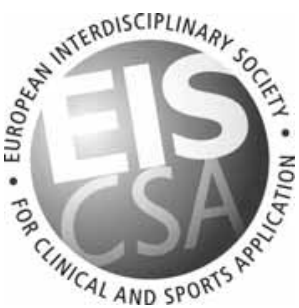

following please find some interesting news about our society:

\section{Website www.eiscsa.com}

Some persons may have tried to access the website www.e-i-s.org and found that it is no longer active. Please feel invited to visit our new website, which can be found under new domain www.eiscsa.com

Also, the secretariat can now be reached through e-mail address: info@eiscsa.com.

\section{General Assembly 2005}

This year's GA will take place on the evening of Friday, June 10th in Frankfurt a.M., Germany. Our Honorary President, Prof. Dr. D. Schmidtbleicher will organize the assembly, and you will receive your invitation by separate mail.

\section{Proposal for revised statutes}

The society has undergone quite some changes in the past years. To cope with all changes required, and to keep the society fit for a promising and challenging future, the boards have come to the conclusion that statutes should be revised. The proposal for revised statutes can be viewed on our website from the middle of May onwards. It will be discussed at the GA, and if no major adjustments have to be made, brought to be decided to be accepted by the GA.

\section{Congress 2006}

The fourth Congress of the EISCSA will take place on April 20/21 2006 in Graz, Austria. Make sure to mark it in your calendars early enough. It will have a huge impact, as we will be able to present well-renowned speakers and attract a large number of visitors, not only from Austria, but also from various surrounding countries like Slovenia, Czech Republic, Slovakia, Poland, Croatia, Bosnia and Herzegovina, Serbia-Montenegro, Ukraine and many more.

\section{EISCSA Workshops at the EDEN Reha, Rehabilitation Clinic in Donaustauf, Germany}

In November 2004 and in April 2005, EISCSA held two local workshops in collaboration with the Rehabilitation Clinic EDEN Reha in Donaustauf in Germany. Andreas Schlumberger, a member of the Scientific Board of the EISCSA, and Klaus Eder, the Senior Physiotherapist of the German National Soccer Team and the German Olympic Team, presented new scientific aspects and practical applications on "Stretching and Eccentric Strength Training". Altogether 125 attendees (physiotherapists, coaches of the German Track and Field Association and coaches of the German Weightlifting Association) participated in the two workshops.

We thank you for your support of EISCSA.

With best regards,

Sven Widmer

Secretariat EISCSA 


\section{Membership Form 2005}

$\square$ Yes, I want to confirm my membership with the EISCSA society for the year 2005!

$\square$ Yes, I want to become a new member of the EISCSA society for the year 2005 !

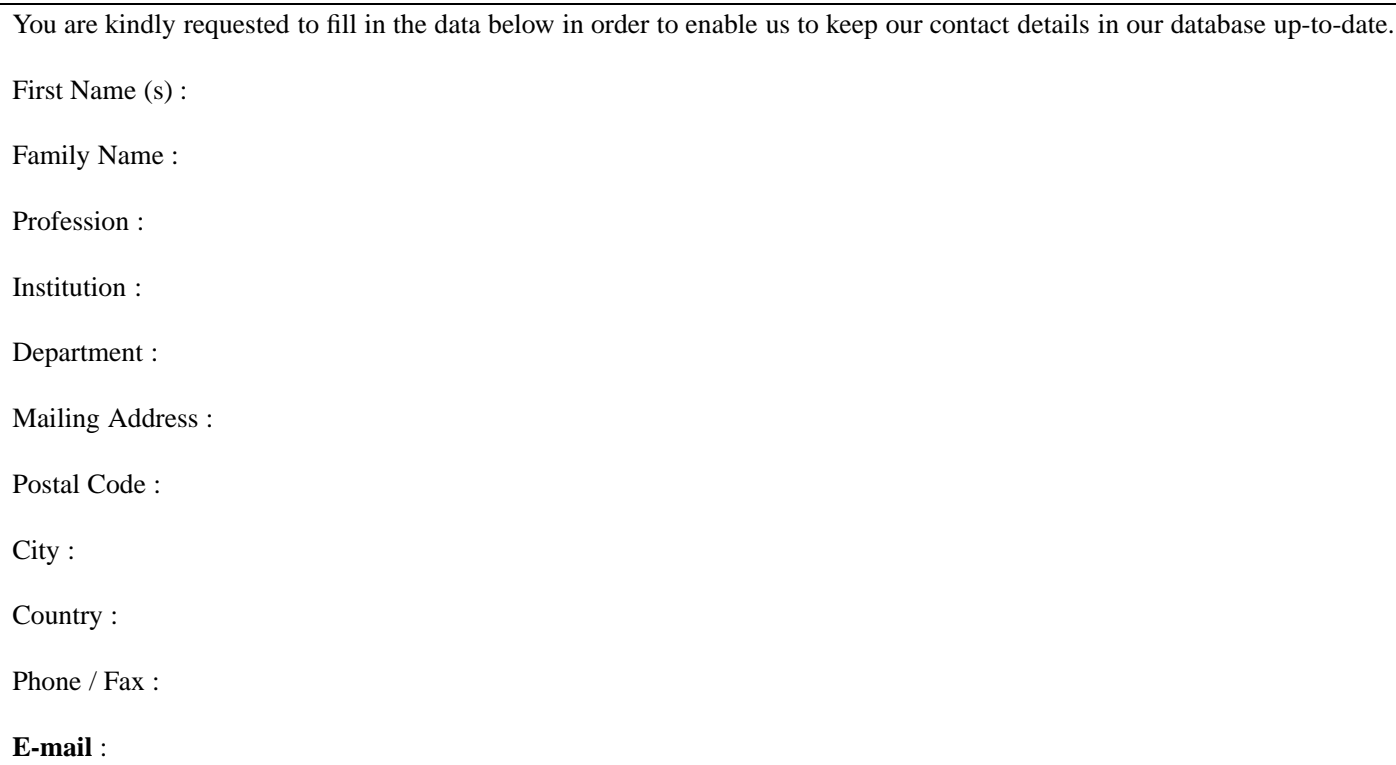

$\square$ I will pay my membership fee of EUR 80 by bank transfer to the account number 53.36.93.152 of the ABN AMRO Bank, Sas Van Gent, The Netherlands, SWIFT Code ABNANL2A

Signature

You are kindly requested to return the completed form by mail, by e-mail or by fax to our number +41180306 29. Please be informed that the membership will automatically renew for another year unless cancelled by written notification to the secretariat at least three months prior to expiry. Thank you for taking note.

$\begin{array}{ll}\text { EISCSA-Secretariat: } & \text { Lochaeckerstrasse 18, CH-8302 Kloten, Switzerland } \\ & \text { Phone: +41 180306 30 Fax: +41 } 18030629 \\ & \text { E-mail: info@eiscsa.com www.eiscsa.com }\end{array}$

